\title{
The Role of Organized Sports Participation during Adolescence in Adult Physical Activity Patterns
}

\author{
Lorena GIL de MONTES* • Jose A. ARRUZA** Silvia ARRIBAS** \\ Susana IRAZUSTA ${ }^{* * *} \cdot$ Saioa TELLETXEA*
}

\begin{abstract}
A $\mathrm{n}$ active adult lifestyle is related to higher quality of life regarding

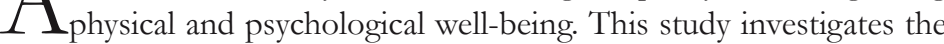
influence of organized sports participation during adolescence in adult physical activity in a retrospective way. A sample of participants living in the north of Spain was asked to report the minutes invested in vigorous, moderate and walking activities during the last seven days. Results showed that those who had been sports club members or had participated in competition prior to the age of 16 had spent a longer time on vigorous activities and a lesser amount of minutes on walking during the last seven days. Implications of adolescent organized sport for continuity of physical activity in adulthood are discussed.
\end{abstract}

Keywords: physical activity, sport, vigorous, active lifestyles, adulthood.

An active lifestyle is related to fewer coronary disease problems, fewer rates of heart disease and less diabetes. On a psychological level, physical activity promotes psychological well-being by reducing feelings of depression and anxiety (Aarts, Paulussen, \& Schaalma, 1997; Mutrie \& Faulkner, 2004). If we could identify the factors that determine leading an active or inactive adult life, we would be able to help improve the quality of life in adulthood.

\footnotetext{
* Department of Social Psychology and Methodology of Behavioral Sciences, University of the Basque Country, San Sebastian, Spain

${ }^{* *}$ Musical and Plastic Expression and Body Language Department, University of the Basque Country, San Sebastian, Spain

${ }^{* * *}$ Department of Physical education and Sport, University of the Basque Country, Vitoria, Spain
} 
Previous research has shown that sports participation in adolescence is one of the determinants for leading an active life during adulthood (BarnekowBergkvist, Hedberg, Janlert, \& Jansson, 1998; De Bourdeaudhuij, Sallis, \& Vandelanotte, 2002; Engström, 1986; Trost, Owen, Bauman, Sallis, \& Brown, 2002). This trend is particularly strong in those people who practiced sports vigorously during adolescence, that is, those who have been engaged in sports as club members and in competition (Curtis, Mc'Teer, \& White, 1999; Hirvensalo, Lintunen, \& Rantanen, 2000; Telama, Yang, Viikari, Välimäki, Wanne, \& Raitakari, 2005). Most of these studies have aimed at predicting ratios of active and inactive people in the adult population. However, less is known about how adolescent participation in intensive sports affects the prevalence of different patterns of physical activity. Actually, it may be that adolescent sport participation relates differently to adult vigorous, moderate or light physical activity. Thus, in this investigation we addressed the following question: Is the time invested in vigorous, moderate and walking activities in adulthood related to having participated in organized sports during adolescence?

Participating in sports is an important part of the self-concept for many adolescents (Ferron, Narring, Cauderay, \& Michaud, 1999; Moreno, Cervelló, Vera, \& Ruiz, 2007). Sports participation allows demonstration of competence in an activity that is positively valued in our culture. In fact, several studies indicate that adolescent sports participation is related to self-esteem (Donaldson \& Ronan, 2006; Pastor \& Balaguer, 2001). Besides, sports participation provides adolescents with a valued social network (Sallis, Prochaska, \& Taylor, 2000). According to continuity theory (Atchley, 1989), as people become older, they are predisposed and motivated to preserve or maintain important aspects of their past self-concept. This motivation leads people to continue performing past behavior that has become a significant part of their self-definition. Continued performance of such behavior in the aging process renders a feeling of mastery and competence to the activity, a sense of ego integrity, a higher self-esteem, and it enables important needs such as social interaction to be met. Notwithstanding, continuation of sports and physical activity participation in later ages does not necessarily mean that the activity should be done in the same fashion (Langley \& Knight, 1999). In the aging process, people change or adapt past behavior to their current reality. Continuity of sports and physical activity participation in adult age requires adapting the activity at least to availability of free time and, more importantly, to functional ability.

Continuity of sports and physical activity during the lifespan means having to adapt the activity to a life involving professional demands, and later to a retired life. To fully grasp the evolution of sports and physical activity we cannot limit the measurement of such activities to leisure time, but we should also measure 
physical activity at other moments of the day. However, the literature in this domain has used measures of physical activity displayed in adulthood consistently confined to leisure time activities, excluding all physical activity that occurs in other kinds of contexts, such as home or work contexts where most people spend the largest part of their everyday life (Ommundsen, Klasson-Heggebo, \& Anderssen, 2006; Timperio et al., 2006). Even if the level of physical activity at work may depend on the kind of occupation people engage in, there are still occasions on which people can make decisions about how to commute to work, whether to take the stairs or use the lift to reach a second floor, or about the way shopping is done. These everyday life choices are meaningful in the context of continuity of physical activity in adult life.

Furthermore, the examination of sports and physical activity continuity throughout the lifespan should consider a wide range of physical activities to be reliable. Otherwise, declines in physical activity can be confounded with change or even evolution of physical activity participation (Frändin, Mellström, Sundh, \& Grimby, 1995; Leinonen, Hekkinen, \& Jylhä, 2001). This change may occur in the elderly once functional abilities start to evidence limitations. In these cases, people may give up intensive physical activities and replace them with lighter physical activities that allow them to maintain an active lifestyle. This limitation however, does not only concern age, but also the evolution from organized forms of physical activity to recreational physical activity. Restricted measures of physical activity participation may confound the differences between discontinuation of organized sports with the adoption of recreational forms of physical activity that include non-conventional types of physical activity, such as walking and yoga, etc. Similarly, not regarding this kind of physical activity necessarily leads to a downgrading of forms of women's physical activity, which in many cases are not properly represented in organized or federative sports (Davison, Werder, Trost, Baker, \& Birch, 2007; Vilhjalmsson \& Kristjandnsdottir, 2003). These forms of physical activities might be measured by registering the time people invest in activities of diverse intensities: from engaging in sports or walking to cleaning windows, working in construction or commuting.

Thus, this research hypothesized that people who have engaged in organized sports during adolescence are likely to spend a longer time on vigorous physical activities of any kind. In contrast, those who prior to the age of 16 have practiced no sports or have done it in non-organized ways are likely to invest less time in vigorous activities and a longer time in mild physical activities. In this way, adults are expected to continue to exercise in ways that are consistent with previous self concepts regarding sports and physical activity. 
This study aims to compare the time that adults over the age of 18 invest in physical activities of varied intensity as a function of the type of sports participation they were engaged in prior to the age of 16. Specifically, the time invested over the last seven days in any context (home, work, leisure) in light (walking), and moderate and vigorous physical activities was examined and compared in three groups of adults (a group that had been involved in sports as club members prior to the age of 16, a group of adults who participated in organized sports at school and a group of adults that did not participate in any organized form of physical activity prior to the age of 16). As this is a retrospective study, several variables have been controlled, which have also been regarded as control variables in similar studies. In particular, age, occupation and level of education were included in the analyses as covariates (Curtis, et al., 1999).

\section{Method}

Participants. This study is part of a larger project about sports participation in adulthood in the region of Gipuzkoa (Spain). The original sample consisted of 1008 people (18 to 92 years old, SD = 19.9). Data was collected during March 2005. The date was intentionally established in order to select an ordinary week of the year. This criterion should guarantee a representative measure of physical activity in the last seven days. The sample was representative of Gipuzkoa, and stratified according to regional area and population size, while using gender and age quotas (504 women and 504 men), age (144 from 18 to 24, 288 from 25 to 44, 288 from 45 to 64 and 288 older than 65) to represent the regional area of Gipuzkoa. In the sample, 51\% had completed compulsory education, 35.3\% secondary school and 14\% had also completed university studies. Participants were interviewed individually at their homes to ensure appropriate understanding and that there were no missing data.

The categorization of adolescent sports participation was created by dividing participants into three groups. The first group included participants who had not participated in sports or who had not done any kind of organized sports during adolescence $(\mathrm{n}=528,60.4 \%$ women). The second group included those who had participated in sports at school, either competitively or non-competitively, but had not been involved in sports at the sports club level $(\mathrm{n}=241,47.4 \%$ women). The third group included those participants who had been members of a sports club during adolescence, regardless of the competitive nature of this participation ( $n=208,27 \%$ women). Of the 1008 people, 14 experienced limitations in performing physical activity (temporary or permanent illnesses or injuries). An additional 17 people had missing values on their questionnaires in relation to their physical activity involvement. In the analyses regarding adolescent sports participation, 75 people reported having participated in sports dur- 
ing adolescence but were not sure whether it was organized at school or at club membership level, and so they were excluded from the analyses.

Physical activity measure. Physical activity was measured by the International Physical Activity Questionnaire (previous 7 days' version, IPAQ). This physical activity measure has been regarded as a reliable and valid self-report measure (Brown, Trost, Bauman, Mummery \& Owen, 2004; Craig et al., 2003). This instrument measures time invested in three kinds of physical activity: the number of minutes spent doing vigorous, moderate and walking activities during the previous seven days. The recommendations proposed by the IPAQ research committee were rigorously followed by adapting the Argentinean version to vernacular Spanish. This version was translated again into English and two judges reached consensus on disagreements. This version was pilot tested with 100 people fluent in Spanish. The pilot test also checked for the clarity of the questions. A final version was obtained as a result.

The number of minutes of vigorous, moderate and walking activity was calculated by multiplying minutes invested in the three activities per session by the number of days per week in which each session was performed (Craig et al., 2003; Ainsworth et al., 2000). The number of minutes of physical activity is not normally distributed in the population. As a consequence, the scores were transformed into ranks (Conover \& Iman, 1981; Zimmerman, 2004). All analyses include rank order dependent variables.

\section{Data analysis}

Preliminary analyses were carried out to provide descriptive scores regarding time spent on vigorous, moderate and walking activity according to age and sex. Further analyses were not done separately according to gender due to the small amount of women who had participated in organized sports during adolescence. Age is held as a covariate in all analyses, except in multiple comparison tests. The influence of adolescent organized sports participation on adult physical activity minutes was examined via a repeated measure ANOVA. Further analyses of variance were carried out to gain a closer look at the differences among groups. The three analyses present an increasing difference between groups in terms of sports participation intensity levels. In particular, the first analysis compared those who had participated in adolescent organized school sports to those who had not participated in organized school sports. The second analysis compared the adolescent sports club member group to participants who were not members of any sports club during adolescence. Finally, people who had participated in competition were compared to those who had not participated in them. 
These analyses maintained age as a covariate. The role of other covariates such as current profession and educational status were examined in the main analysis. All analyses were performed using the SPSS statistical package, version 14.

\section{Results}

Table 1 shows descriptive scores. In this Table the mean ranks revealing the role of gender and age on the minutes spent carrying out vigorous, moderate and walking activities can be observed.

Table 1. Mean ranks of vigorous, moderate and walking physical activity as a function of gender, age and gender by age interaction

\begin{tabular}{lcccc}
\hline & $\mathbf{n}$ & Vigurous & Moderate & Walking \\
\hline Male & 495 & 529 & 478 & 494 \\
Female & 489 & 478 & 517 & 508 \\
Age & & & & \\
$\mathbf{1 8 - 2 4}$ & 142 & 578 & 445 & 361 \\
$\mathbf{2 5 - 4 4}$ & 282 & 579 & 540 & 441 \\
$\mathbf{4 5 - 6 4}$ & 276 & 488 & 510 & 573 \\
$\mathbf{6 5 +}$ & 284 & 406 & 471 & 560 \\
\hline Gender x age & & & & \\
Male & & & & \\
$\mathbf{1 8 - 2 4}$ & 71 & 634 & 446 & 319 \\
$\mathbf{2 5 - 4 4}$ & 143 & 630 & 525 & 401 \\
$\mathbf{4 5 - 6 4}$ & 139 & 489 & 465 & 582 \\
$\mathbf{6 5 +}$ & 142 & 412 & 460 & 589 \\
\hline Female & & & & \\
$\mathbf{1 8 - 2 4}$ & 71 & 522 & 444 & 404 \\
$\mathbf{2 5 - 4 4}$ & 139 & 527 & 554 & 482 \\
$\mathbf{4 5 - 6 4}$ & 137 & 487 & 555 & 565 \\
$\mathbf{6 5 +}$ & 142 & 400 & 482 & 531 \\
\hline
\end{tabular}

The main analysis was aimed at examining the influence of adolescent organized sports participation on time spent carrying out different types of physical activity in adulthood. Adolescent sports participation was introduced in the repeated measure ANOVA as an independent measure - type of physical activity as a repeated measure - while age was utilized as a covariate. Results 
revealed an interaction effect between the covariate (age) and type of physical activity $F(2,1946)=59.53, p<.0001$, and an interaction between adolescent sports participation and time spent on each type of physical activity $F(4,1946)=$ $2.71, p<.03$ (Table II). The same analysis carried out after including occupation and education level did not alter the significant interaction $F(4,1946)=17.32$, $p<.0001$ and $F(4,1946)=8.609, p<.0001$, respectively. Significance level in multiple comparisons among means was adjusted to $p<.01$.

Closer inspection of the means showed that the non-organized sports participation group spent less time on vigorous activities than on walking $(p<.004)$, and less time on moderate activities than on walking $(p<.0001)$. The sports club participation group, though, spent greater time on vigorous physical activity than on moderate $(p<.0001)$ and walking activity $(\phi<.0001)$. In relation to physical activity, the differences were mainly due to the time spent on vigorous and walking activity. In the case of vigorous activities, the non-organized participation group spent less time than the school sports participation $(p<.0001)$ and the sports club participation groups $(p<.0001)$. No differences between groups were found in the time spent on moderate activities. Time spent on walking, however, was significantly greater in the non-organized participation group than in the sports club participation group $(p<.0001)$.

Table 2. Mean ranks of vigorous, moderate and walking physical activity as a function of type of adolescent sports participation, adjusted according to age.

\begin{tabular}{lcccc}
\hline Adolescent participation & $\mathbf{n}$ & Vigurous & Moderate & Walking \\
\hline Non-organized & 528 & $466 \mathrm{a}$ & $508 \mathrm{~b}$ & $543 \mathrm{c}$ \\
Sports at school & 241 & 523 & 501 & 481 \\
Sports club member & 208 & $582 \mathrm{a}$ & $473 \mathrm{~b}$ & $429 \mathrm{~b}$ \\
\hline
\end{tabular}

In order to examine more closely the influence of adolescent sports participation prior to the age of 16 on adult physical activity, three further analyses of variance were conducted. The first analysis of variance aimed at analyzing the influence of adolescent school sports participation on time spent involved in adult forms of physical activity. The dichotomous variable of school sports participation (participation vs. non-participation) was introduced in the analysis as an independent measure and the type of physical activity (vigorous, moderate and walking) was included as repeated measures. Age was introduced as a covariate. The results of this analysis indicated a significant main effect for physical 
activity $F(2,1948)=61.508, p<.0001$ and for the interaction between physical activity and age $F(2,1948)=65.184, p<.0001$. No significant interaction was obtained $F(2,1948)=1.117$.

A second analysis of variance was conducted in order to examine the effect of adolescent sports club participation (member vs. non-member) on time spent involved on each type of physical activity. Adolescent sports club membership was introduced in the analysis as an independent measure and physical activity as a repeated measure. Age was included as a covariate. The results revealed a significant main effect for physical activity $F(2,1792)=72.408, p<.0001$, and a significant interaction between physical activity and the covariate (age) $F(2$, $1792)=64.234, p<.0001$, and the analysis was also characterized by the interaction between adolescent sports club membership and the type of current physical activity $F(2,1792)=3.758, p<.024$. Multiple comparisons among mean ranks led us to adjust significance level to $p<.01$.

The means revealed that participants who had been members of a sports club prior to the age of 16 spent significantly more time on vigorous activities than they did on moderate $(p<.0001)$ and walking activities $(p<.0001)$. Participants who had not been members of a sports club prior to the age of 16 however, spent a longer time walking than they did on vigorous activities $(p<.0001)$. In addition, differences between the sports club members and non-members were mainly due to involvement in vigorous $(\mathrm{p}<.0001)$ and walking physical activity $(\phi<.0001)$, suggesting that the former spend a greater amount of time on vigorous activities and the latter on walking.

Table 3. Mean ranks of vigorous, moderate and walking physical activity as a function of adolescent sports club participation, adjusted according to age.

Adolescent participation

\begin{tabular}{lcccc}
\hline Sports club membership & $\mathbf{n}$ & Vigurous & Moderate & Walking \\
\hline No membership & 694 & $480 \mathrm{a}$ & 504 & $524 \mathrm{~b}$ \\
Sport club membership & 205 & $584 \mathrm{a}$ & $471 \mathrm{~b}$ & $428 \mathrm{~b}$ \\
\hline
\end{tabular}

A final analysis of variance was conducted with only a part of the sample. Specifically, those participants who reported having participated in competitive events of any kind prior to the age of 16 were compared to the sub-sample of participants who had not participated in competitive events prior to the age 
of 16. The sample size in this analysis was 276. Participation in competition (competition vs. non-competition) was introduced as an independent measure and physical activity (vigorous, moderate or walking) as a repeated measure, with age being the covariate. A significant main effect was obtained for physical activity $F(2,256)=20.841, p<.0001$ and an interaction between physical activity and age as covariate $F(2,546)=p<.0001$. The analysis was qualified by an interaction between adolescent participation at a competitive level and physical activity $F(2,546)=4.678, p<.01$. Significance level was again adjusted to $p<0.01$ to conduct the multiple comparisons.

Results indicated that the differences in time spent on physical activity were mainly due to those people who had participated in competition. Specifically, this group spent a longer time on vigorous activities than on moderate activities $(p<.0001)$ or walking $(p<.0001)$. No significant differences in time spent on physical activities were obtained in the group that had not participated in sports competition. Differences between the competition and non-competition groups were mainly due to time spent on vigorous $(p<.02)$ and moderate physical activity $(\phi<.04)$, albeit not significant on a conservative level.

Table 4. Mean ranks of vigorous, moderate and walking physical activity as a function of adolescent competitive participation adjusted according to age.

Adolescent participation in competition

\begin{tabular}{lcccc}
\hline & $\mathbf{n}$ & Vigurous & Moderate & Walking \\
\hline No competitive & 96 & 519 & 534 & 504 \\
Competitive & 180 & $586 \mathrm{a}$ & $463 \mathrm{~b}$ & $428 \mathrm{~b}$ \\
\hline
\end{tabular}

\section{Discussion}

The results of this investigation suggest that the time invested in vigorous, moderate and walking activities in adulthood is related to organized sports participation experienced during adolescence. The study indicates that the group of adults who were members of a sports club prior to the age of 16 invests a greater amount of time in vigorous physical activities than the group of adults who did not participate in organized forms of sport. In contrast, the former spends less time on walking than the latter. Participating in sports at school may not be enough to continue physical activity in adulthood. More intensive 
participation might be needed. Actually, organized sports provide adolescents with a significant social network and with new criteria for self-definition (Raudsepp, Liblik, \& Hannus, 2002). If sports and physical activity become a valued part of the self concept, people striving for self-consistency are likely to get involved in associated behavior later in adulthood (Atchley, 1989). This study suggests that continuity of sports and physical activity occurs regarding intensity, but not necessarily in the same activity. These results are consistent with other studies, both retrospective and longitudinal, that point to the nature of organized and competitive sports participation as leading to the continuity of vigorous physical activity participation in adulthood (Curtis et al., 1999; Hirvensalo et al., 2007).

In this study, a representative sample has been used, with ages varying from 18 to 92 . The literature on this topic suggests that in these kinds of retrospective studies it is necessary to control for age, a variable that plays a confounding role in the prediction of physical activity participation (Curtis et al., 1999). In this study, age, occupation and education level are significant covariates and determine the level of physical activity. As covariates, however, they do not alter the significant role that a history of organized participation plays in the continuity of physical activity in adulthood. Thus, the confounding role of these variables has been isolated in the analyses.

In contrast to previous studies, the adult physical activity measure used in this study allows for the consideration of physical activity performed in any context, not only physical activity that occurs during leisure time. Indeed, we suggest that adolescent sports participation may determine the type of active or inactive lifestyle that people maintain in adulthood -during work, in leisure time, or in the home-. This is a relevant aspect of this study that, as far as we know, is absentin other studies of this kind, and points to the conclusion that adolescent participation is not only related to adult physical activity in leisure time but also in other contexts.

Moreover, using a measure of the time spent on vigorous, moderate and light physical activities enables further information to be gathered about the way people engage in physical activity. Specifically, it reveals that people might compensate for the intensity in their physical activities and the time they invest in it. Therefore, people who invest a greater amount of time in vigorous physical activity tend to reduce the time dedicated to light activities, whereas those people who predominantly engage in low intensity activities, do so at the expense of vigorous activities.

The study leaves questions open to answer regarding the differences between men and women with regard to the effect of adolescent organized sports participation on adult physical activity. Undoubtedly, larger samples would be needed to appropriately examine the role that gender differences make evident 
in this context. Another aspect that is worthy of greater scrutiny is the relation between organized and intense participation. Even if the study indicates that there are differences in terms of adult physical activities as a function of adolescent organized participation, the study does not provide an explanation as to whether adult physical activity is determined by the organized nature of participation or by the intensity of participation. Further studies should address these questions more in depth.

In short, this retrospective study indicates that people who invest more time in vigorous activities in adulthood report having participated intensively in sports during adolescence. In contrast, adults who invest more time in light activities, such as walking, report having exercised more lightly during adolescence. Presumably, adolescent sports participation might have become an important aspect of their self concept. As people advance in age, they may hold tightly to the self concept and strive for consistency by persisting in these highly valued activities. If this were the case, improving organized sports programs to enable adolescents to participate and to enjoy of sports and physical activity might be a promising opportunity to help them become active adults.

\section{Acknowledgements}

This work was supported by the Spanish Department of Science and Technology [DEP2006-56054-C03-01/AC'TI]; and the Department of External Action and Sports of the Provincial Council of Gipuzkoa [02-FA/OF-2232008]. We thank Robert Brustad for his valuable comments on earlier drafts of this paper. Elaboration of this article was managed by using the online research unit of sports: http://www.ehu.es/cinvidere/Paginas/Cinvidere_ING.html

\section{References}

Aarts, H., Paulussen, T., \& Schaalma, H. (1997). Physical exercise habit: On the conceptualization and formation of habitual health behaviors. Health Education Research, 12, 363-374.

Ainsworth, B. F., Haskell, W. L., Whitt, M. C., Irwin, M. L., Swartz, A. M., Strath, S. J., et al. (2000). Compendium of physical activities: An update of activity codes and MET intensities. Medicine \& Science in Sports \& Exercise, 32, 498-516.

Atchley, R. C. (1989). A continuity theory of normalaging. Gerontologist, 29, 183-190.

Barnekow-Bergkvist, M., Hedberg, G., Janlert, U., \& Jansson, E. (1998). Prediction of physical fitness and physical activity level in adulthood by physical 
performance and physical activity in adolescence - An 18-year follow-up study. Scandinavian Journal of Medicine and Science in Sports, 8, 299-308.

Brown, W. J., Trost, S. G., Bauman, A., Mummery, K., \& Owen, N. (2004). Testretest reliability of four physical activity measures used in population survey. Journal of Science and Medicine in Sport, 7, 205-215.

Conover, W. J., \& Iman, R. L. (1981). Rank transformations as a bridge between parametric and nonparametric statistics. The American Statistician, 35, 124-129.

Craig, C. L., Marshall, L., Sjöström, M., Bauman, A. E., Booth, M. L., Ainsworth, B. E., et al. (2003). International Physical Activity Questionnaire: 12-country reliability and validity. Medicine \& Science in Sports \& Exercise, 35, 1381-1395.

Curtis, J., McTeer, W., \& White, P. (1999). Exploring effects of school sport experiences on sport participation in later life. Sociology of Sport Journal, 16, 348-465.

Davison, K. K., Werder, J. L., Trost, S. G., Baker, B. L., \& Birch, L. L. (2007).

Why are early maturing girls less active? Links between pubertal development, psychological well being, and physical activity among girls at ages 11 and 13 . Social Science \& Medicine, 64, 2391-2404.

De Bourdeaudhuij, I., Sallis, J., \& Vandelanotte, C. (2002). Tracking and explanation of physical activity in young adults over a 7-year period. Research Quarterly for Exercise and Sport, 73, 376-385.

Donaldson, S. J., \& Ronan, K. R. (2006). The effects of sports participation on young adolescents' emotional well-being. Adolescence, 41, 369-389.

Engström, L. (1986). The process of socialization into keep-fit activities. Scandinavian Journal of Sports Science, 8, 89-97.

Ferron, C., Narring, F., Cauderay, M., \& Michaud, P. A. (1999). Sport activity in adolescence: associations with health perceptions and experimental behaviors. Health Education Research, 14, 225-233.

Frändin, K., Mellström, D., Sundh, V., \& Grimby, G. (1995). A life span perspective on patterns of physical activity and functional performance at the age of 76. Gerontology, 41, 109-120. 
Hirvensalo, M., Lintunen, T., \& Rantanen, T. (2000). The continuity of physical activity - a retrospective and prospective study among older people. Scandinavian Journal of Medicine and Sports, 10, 37-41.

Langley, D. J., \& Knight, S. M. (1999). Continuity in sport participation as an adaptive strategy in the aging process: A lifespan perspective. Journal of Aging and Physical Activity, 7, 32-54.

Leinonen, R., Hekkinen, E., \& Jylhä, M. (2001). Predictors of decline in selfassessments of health among older people- a 5-year longitudinal study. Social Science \& Medicine, 52, 1329-1341.

Moreno, J. A., Cervelló, E., Vera, J. A., \& Ruiz, L. M. (2007). Physical self-concept of Spanish schoolchildren: Differences by gender, sport practice and levels of sport involvement. Journal of Education and Human Development, 1, 1-16.

Mutrie, N., \& Faulkner, G. (2004). Physical activity: Positive psychology in motion. In P. A. Linley, \& S. Joseph (Eds), Positive psychology in practice (pp. 146164). New Jersey: John Wiley \& Sons.

Ommundsen, Y., Klasson-Heggebo, P., \& Anderssen, S. A. (2006). Psycho-social and environmental correlates of location-specific physical activity among 9and 15- year-old Norwegian boys and girls: The European youth heart study. International Journal of Behavioral Nutrition and Physical Activity, 3, 1-13.

Pastor, Y., \& Balaguer, I. (2001). Relaciones entre autoconcepto, deporte y compe tición deportiva en los adolescentes valencianos. Psicologia-online, 56 from http://www.psicologia-online.com/ciopa2001/actividades/57/index.html.

Raudsepp, L., Liblik, R., \& Hannus, A. (2002). Children's and adolescents' physi cal self-perceptions as related to moderate to vigorous physical activity and physical fitness. Pediatric Exercise Science, 14, 97-106.

Sallis, J. F., Prochaska, J. J., \& Taylor, W. C. (2000). A review of correlates of physical activity of children and adolescents. Medicine \& Science in Sports \& Exercise, 32, 963-975.

Telama, R., Yang, X., Viikari, J., Välimäki, I., Wanne, O., \& Raitakari, M. D. (2005). Physical activity from childhood to adulthood: A 21-year tracking study. American Journal of Preventive Medicine, 28, 267-273. 
Timperio, A., Ball, K., Salmon, J., Roberts, R., Giles-Corti, B., Simmons, D., et al. (2006). Personal, family, social, and environmental correlates of active commuting to school. American Journal of Preventive Medicine, 30, 45-51.

Trost, S. G., Owen, N., Bauman, A. E., Sallis, J. F., \& Brown, W. (2002). Correlates of adults' participation in physical activity: Review and update. Medicine \& Science in Sports \& Exercise, 34, 1996-2001.

Vilhjalmsson, R. \& Kristjandnsdottir, G. (2003). Gender differences in physical activity in older children and adolescents: The central role of organized sport. Social Science \& Medicine, 56, 363-374.

Zimmerman, D. W. (2004). An extension of the rank transformation concept. Journal of Experimental Education, 61, 73-80.

Lorena GIL de MONTES is associate professor in the Department of Social Psychology and Methodology of the behavioral sciences at the University of the Basque Country. She obtained her PhD in 2001 and since then she has been working about the role of social psychological variables in sports and physical activity behavior. One of her main projects consists of a follow up study of physical activity behavior as it relates to physical self-concept, motivation, health and other variables in the adult population. E-mail address: lorena.gil@ehu.es

Silvia ARRIBAS GALARRAGA, Ph.D. has a degree in Physical Education and Ph. Dr. in Science in Education. Since 1996, she teaches physical education for teacher training at the University of the Basque Country (EHU-UPV). With research activity recognized by the Spanish government (CENAI), is author of numerous scientific articles and director of several research projects in the field of physical education and sports activities. Today, is principal investigator of the research group Ikerki 05/30 at the University of Basque Country. E-mail address: silvia.arribas@ehu.es

Susana IRAZUSTA ADARRAGA, Ph.D. is a professor of University of the Basque Country since 1990. Degree in physical education and Ph.D. Pedagogy section since 2000. Director of Social Research Laboratory, Faculty of Physical Education. Participant in numerous research projects in physical activity and sport. Coordinator of a project on motor competence and perceived competence of students in the CTP (Community of Pyrenees). With recognized research section. Publications in various journals of physical education and sport. Currently invited by Segalen University of Bordeaux to teach the Master 1 and 2 in board sports and Management 1 and 2 sport in the course 2011/12. susana. E-mail address: irazusta@ehu.es 
Jose Antonio ARRUZA, Ph.D. Professor and the founder of Ikerki research group. Author of numerous articles on self-efficacy and mood psychosocial variables in journals such as Journal of Sport Behavior, Perceptual and Motor Skills, 2009, Journal of psychology. Personal trainer in Barcelona 92, Atlanta 96, Sydney-2000, Athens 2004; Teskal Creator tool for intervention in high-performance athletes. In 1 retired now in college, working with high performance athletes. E-mail address: josean.arruza@gmail.com

Saioa TELLETXEA, Ph.D. is a professor in the department of Social Psychology and Methodology since 2006 at the University of the Basque Country. Participate in the research on diagnosis and assessment of sport and physical activity and intervention training related to physical and sports activities. E-mail address: saioa.telletxea@ehu.es 